\title{
Serving size in the eye of the beholder
}

Published online: 02 August 2012

(C) Springer Healthcare 2012

MedWire News: Canadian study findings suggest that many people overestimate the size of one serving of food and may overeat as a result.

"What we found was that the way people estimate one serving is essentially how much they would normally eat at one time," said study author Jennifer Kuk (York University, Toronto, Ontario) in a press statement.

Kuk and team recruited 145 White, Black, South Asian, and East Asian adults to see whether they would be able to accurately estimate the amount of food constituting one portion according to the Canada Food Guide (CFG), an educational guide produced to help Canadians eat more healthily. The researchers also asked the participants to estimate how many servings they had eaten over the last 24 hours according to the CFG measures.

They found that on average participants estimated one CFG serving of fruit/vegetables and one serving of grains to be significantly larger than the official size, by $43 \%$ and $55 \%$, respectively.

Conversely, one CFG portion of meat alternatives or of cheese was estimated to be a respective $33 \%$ and $31 \%$ smaller than in reality, respectively. Chicken, carrot, and milk portion sizes were guessed accurately by the majority of participants.

On their 24-hour food recall, participants of all ethnicities estimated that they consumed fewer servings of fruit/vegetables (15\%), grains (28\%), and meat and meat alternatives (14\%) than they actually did, and more milk or alternatives (26\%) than they did in reality.

As a consequence, "the majority of participants in the study inaccurately thought they would need to increase their food consumption by approximately 400 calories to meet recommendations in Canada's Food Guide," said Kuk.

"This suggests we either need to change the size of a serving in the Guide - which has remained almost the same since 1977 - or educate Canadians more about how much food they should be consuming in a day," she emphasized.

By Helen Albert, Senior MedWire Reporter

\section{Reference}

Appl Physiol Nutr Metab 2012; 37: 923-930 